\title{
The Political Economy of Fixed Regional Investment Shares with an Illustration for Belgian Railway Investments*
}

\author{
Stef Proost ${ }^{\dagger} \quad$ Vera Zaporozhets ${ }^{\ddagger}$
}

February 2010

\begin{abstract}
Many local public goods are allocated by federal governments using fixed regional shares: every region is entitled a fixed share of the total budget for a particular type of public good. This paper compares this fixed regional sharing rule with two alternative allocation rules: first best and common pool allocation. We find that the fixed regional sharing rule performs relatively well if the regional shares are reasonable. Legislative bargaining theory is used to study the determination of the fixed regional shares.
\end{abstract}

Keywords: local public goods, political economy, railways

JEL codes: H41, H77, L98

\footnotetext{
${ }^{*}$ We thank B. De Borger and A. Glazer for helpful comments on a previous version of this paper and Evi Meire for excellent research assistance.

${ }^{\dagger}$ Katholieke Universiteit Leuven, Faculty of Business and Economics, Belgium (Stef.Proost@econ.kuleuven.be).

${ }^{\ddagger}$ Katholieke Universiteit Leuven, Faculty of Business and Economics, Belgium (Vera.Zaporozhets@econ.kuleuven.be).
} 


\section{Introduction}

In this paper we analyze the allocation of public investments over regions in a federal state. In particular we are interested in the role of the fixed sharing rule. By fixed sharing rule we mean that each region in a federation gets a fixed share of the total budget for a particular public good. This allocation mechanism seems to be present in many federations. It is commonly, but not explicitly, used in the EU to allocate investment money over member countries. It is used in Belgium to allocate federal investment funds to railway projects and as well as being used in many more countries. Economists often consider such an allocation a very inefficient and senseless allocation as there is no explicit optimization of resources over regions. These considerations lead us to the three questions we address in this paper. First, we analyze under what conditions the fixed sharing rule allocation does not depart too far from the first-best and the uncoordinated common-pool allocation. Second, we discuss what mechanism determines the precise fixed sharing rule that is used in a federation. Third, we illustrate the effect of fixed regional investment shares numerically for rail investments in Belgium.

To provide an answer to the first question, we employ a political economy model with the regions as the main players and consider the investments as local public goods. We define three different allocation mechanisms for regional investments. The first-best will serve as a benchmark. The second allocation mechanism is the common-pool allocation, where every region can decide on its own investment level and where all investments have to be financed by federal tax revenues. The third alternative is the allocation of the total investment budget over the regions according to a fixed sharing rule. We show that, in general, the fixed sharing rule performs better than the common pool allocation and approximates the first best if fixed regional shares are reasonable.

We use two variants of a legislative bargaining model to study the determination of the fixed regional shares. In the first variant the share of each region is equal to its equilibrium expected share from the bargaining game. The main implication of the model is that, the stronger the region in terms of proposal power, the bigger is its share in the federal budget. 
In the second variant considered in this work we introduce the possibility to deter cheating on agreed shares by a temporary majority or an agenda setter. We show that, under rather general conditions, reasonable fixed shares can be supported as an equilibrium allocation.

We illustrate the results and the welfare effects of the alternative regional allocations for rail investments in Belgium. Currently rail investment expenditures in Belgium are decided and paid by the federal government in agreement with the regions. It seems that no political agreement is possible if the rail investment expenditures do not follow a historical sharing rule of $60 \%$ for Flanders and $40 \%$ for the Walloon region. One of our main findings for this example is that the fixed 60/40 sharing rule for federal funds in Belgium does not necessarily generate large efficiency losses.

\subsection{Related Literature}

One of the main concerns of public and political economists is the inefficiency of local public goods provision by a central legislature. Starting with Tullock (1959) and Weingast et al. (1981), economists have modelled fiscal policy in democratic regimes as a common pool problem and address the question of fiscal inefficiency in the form of excessive spending. The reason of this inefficiency is that the benefits are concentrated in specific jurisdictions while the costs are spread across all the jurisdictions.

More recent theoretical studies readdress this problem. For instance, Besley and Coate (2003) incorporate cross-regional spillovers in the model to study which level of government, central or local, should decide on the provision of the local public good.

The empirical issue of the common pool problem also has been tackled in a variety of studies. Among others, Knight (2004) proves existence of the common pool incentives by analyzing 1988 Congressional votes over transportation project funding. It is shown that the probability to gain support for a project by a legislator is increasing in the local spending and decreasing in contributions to the federal tax revenues. This result implies aggregate overspending, especially in politically powerful localities, as well as large deadweight losses.

As an alternative to a common pool allocation, local public goods can be allocated in proportion to some single numerical criterion, such as population. Thus, federal governments 
can entitle each region with a fixed share of the total budget. The cost/surplus sharing problem has been studied from an axiomatic perspective. A comprehensive survey of this strand is provided in Moulin (2002). There are also studies, such as Young et al. (1982), which compare different methods on the basis of certain "fairness" principles. One of the conclusions is that the simple proportional allocation according to a single numerical criterion might be preferable on fairness grounds.

In order to explain the determinants of regional shares as an outcome of a political process, we employ the theoretical legislative bargaining model of Baron and Ferejohn (1989) with a modification: the recognition probabilities vary across the legislators. The most closely related paper in this sense is that of Knight (2005). However, in his work there are only two types of legislators with respect to the recognition probability: members vs. non-members of a transportation committee. Another difference with his paper is that we consider not only a standard infinite version of Baron-Ferejohn model but also an alternative variant, in which we introduce the possibility of punishment to deter deviations from the specified sharing rule.

To the best of our knowledge none of the studies has neither addressed the question of efficiency of fixed sharing rule nor has considered such a rule as an alternative to the inefficient common pool allocation.

\section{The Model and Assumptions}

In this section we describe the setup and the main ingredients of the model. Following Persson (1998) we consider a federal state with $n \geq 2$ regions. Each region has a homogeneous population. The federal government uses federal tax revenue to provide a local public good in those regions.

The federal government uses a labor tax $t$ to finance the provision of the public good $g_{i}$ in region $i=1$..n. We denote by $L_{i}$ the total labor supply in region $i$ and assume that it is fixed. The total pool of tax revenues is then equal to $t \sum_{i=1}^{n} L_{i}$. Since labor supply is fixed, the labor tax does not cause any distortions in the labor market. We assume that the cost 
$c_{i}$ of providing one unit of public good differs among the regions because of geographical characteristics, for instance.

The federal government budget constraint is:

$$
t \sum_{i=1}^{n} L_{i}=\sum_{i=1}^{n} c_{i} g_{i},
$$

from which we can easily express $t$ as:

$$
t=\frac{\sum_{i=1}^{n} c_{i} g_{i}}{\sum_{i=1}^{n} L_{i}} .
$$

The preferences for each region $i$ with respect to the local public good $g_{i}$ and private consumption $q_{i}$ are represented by a quasi linear utility function:

$$
u_{i}=q_{i}+H_{i}\left(g_{i}\right), i=1 . . n \text {. }
$$

In line with the standard assumptions the function $H_{i}\left(g_{i}\right)$ is an increasing and concave benefit function that corresponds to the utility derived by region $i$ from expenditure $g_{i}$ on the public good:

$$
H_{i}(0)=0, H_{i}^{\prime}\left(g_{i}\right)>0 \text { and } H_{i}^{\prime \prime}\left(g_{i}\right)<0, i=1 . . n .
$$

We use the Persson's approach as a starting point but assume specific benefit function $H_{i}$ for each region, because it is possible that the local public good is used more intensively in some regions.

\section{Comparing Different Allocation Rules}

In this section we consider the properties of three alternative allocations. First, we consider the first-best situation where the federal government allocates the public good expenditures to the regions in order to maximize overall federal welfare. Next, we discuss the common-pool allocation. Finally, we analyze the results of the fixed regional sharing rule. 


\subsection{The First-Best Benchmark}

In the first-best equilibrium and in a normative interpretation, a federal policy-maker maximizes a general social welfare function, subject to its budget constraint and having nondistortionary and individualized taxes at its disposal. If we assume that income distribution between the regions does not matter ${ }^{1}$, so that the social welfare function is the simple sum of utilities, we can reach the first best with the undistortive tax on the resources of the federation:

$$
\begin{aligned}
& \max _{g_{i}}\left[(1-t) \sum_{i=1}^{n} L_{i}+\sum_{i=1}^{n} H_{i}\left(g_{i}\right)\right] \\
& \text { s. t. constraint }(1) .
\end{aligned}
$$

After substituting for $t$ from (2) we derive the following first order conditions:

$$
\frac{d H_{i}\left(g_{i}^{F B}\right)}{d g_{i}}=c_{i}, \text { for } i=1 . . n,
$$

where FB stands for the first-best allocation.

This standard result states that the marginal benefit from a unit of local public good investments is equal to its marginal cost.

Notice that the same result can be reached if we assume decentralized decisions: the regional governments have to decide on their own public good provision and pay for it with a local non-distortionary tax.

\subsection{The Non-cooperative Common Pool Solution}

In this subsection, we assume that each region proposes its preferred level of railway investments, knowing that it has to be paid out of federal taxes. All regions do this noncooperatively. Now each region $i$ solves the following maximization problem (taking $g_{i}, j \neq i$

\footnotetext{
${ }^{1}$ Alternatively, we could assume that the federal government has lump sum taxes and transfers and uses a Bergson-Samuelson social welfare function. This would result in another allocation of the numeraire good $c$ but would not affect the allocation of local public goods given the quasi-linear utility function.
} 
as given):

$$
\begin{aligned}
& \max _{g_{i}}\left[(1-t) L_{i}+H_{i}\left(g_{i}\right)\right] \\
& \text { s. t. constraint (1). }
\end{aligned}
$$

Again, after substitution for $t$ from (2), we obtain the preferred investment level for each region:

$$
\frac{d H_{i}\left(g_{i}^{C P}\right)}{d g_{i}}=\frac{c_{i} L_{i}}{\sum_{i=1}^{n} L_{i}}, \text { for } i=1 . . n
$$

where CP stands for the common pool allocation. The level preferred in the common pool allocation is independent of the quantity selected by the other regions because there are no spillovers and all taxes are lump sum. One can notice that

$$
\frac{d H_{i}\left(g_{i}^{C P}\right)}{d g_{i}}<c_{i}=\frac{d H_{i}\left(g_{i}^{F B}\right)}{d g_{i}}
$$

i.e. now the marginal benefit of a unit of the public good is lower than the marginal cost, and therefore, the regions prefer an amount of public good that is larger than the first-best allocation. This implies the higher total expenditure for the public good and the higher tax level.

The over-consumption leads to a welfare loss compared to the first-best allocation.

\subsection{The Fixed Sharing Rule Allocation}

In this subsection we assume a fixed sharing rule: all public good investments are paid out of the federal budget according to the fixed shares $\alpha_{i}$ for each region $i$. We suppose that each $\alpha_{i} \in(0,1)$ and $\sum_{i=1}^{n} \alpha_{i}=1$.

The regional shares are fixed but the total volume of investments is still to be determined. We analyze two extreme assumptions: either the unweighted sum of regional welfares is maximized or there is one region that decides on the total budget, maximizing its own welfare.

We first assume that the federal government maximizes the unweighted sum of regional welfares under a regional fixed sharing constraint. It therefore decides on the total budget 
for local public good provision $G$, which is the sum of all the local public good expenditures, given its budget constraint and the fixed sharing rules for the regions:

$$
\begin{gathered}
\max _{G}\left[(1-t) \sum_{i=1}^{n} L_{i}+\sum_{i=1}^{n} H_{i}\left(g_{i}\right)\right] \\
\text { s.t. constraint }(1), \\
G=\sum_{j=1}^{n} c_{j} g_{j} \\
c_{i} g_{i}=\alpha_{i} G \text { for } i=1 . . n .
\end{gathered}
$$

Notice that the problem is very similar to the first-best allocation problem (3). The difference is that the federal government decides on the total amount of the public good (vs. the individual public good levels) with the additional constraint on the distribution of this amount across the regions according to the fixed sharing rule.

Following our usual substitution of $t$ as well as $g_{i}$ into the utility function, we derive the following first-order conditions:

$$
\sum_{i=1}^{n} \frac{\alpha_{i}}{c_{i}} \frac{d H_{i}\left(g_{i}^{S R}\right)}{d g_{i}}=1
$$

with $g_{i}=\frac{\alpha_{i} G}{c_{i}}$ for $i=1$..n. SR refers to the fixed sharing rule allocation.

There are several conclusions we can draw from expression (9). First, notice that this condition can be rewritten as:

$$
\sum_{i=1}^{n} \frac{\alpha_{i}}{c_{i}}\left[\frac{d H_{i}\left(g_{i}^{S R}\right)}{d g_{i}}-c_{i}\right]=0 .
$$

Since $\alpha_{i} \in(0,1)$, some terms in the square brackets should be non-positive while the other ones should be non-negative. Thus, for some regions $\frac{\partial H_{i}\left(g_{i}^{S R}\right)}{\partial g_{i}} \leq c_{i}$ and for the others the opposite inequality holds. This means that there is, compared to the first best, overprovision in some regions and underprovision in other regions.

Second, there exists a distribution of regional shares which produces the first best allocation. We provide a graphical illustration of this result for the case of two regions. Assume there are two regions $i=1,2$ with the fixed shares $\alpha \in(0,1)$ and $1-\alpha$. 


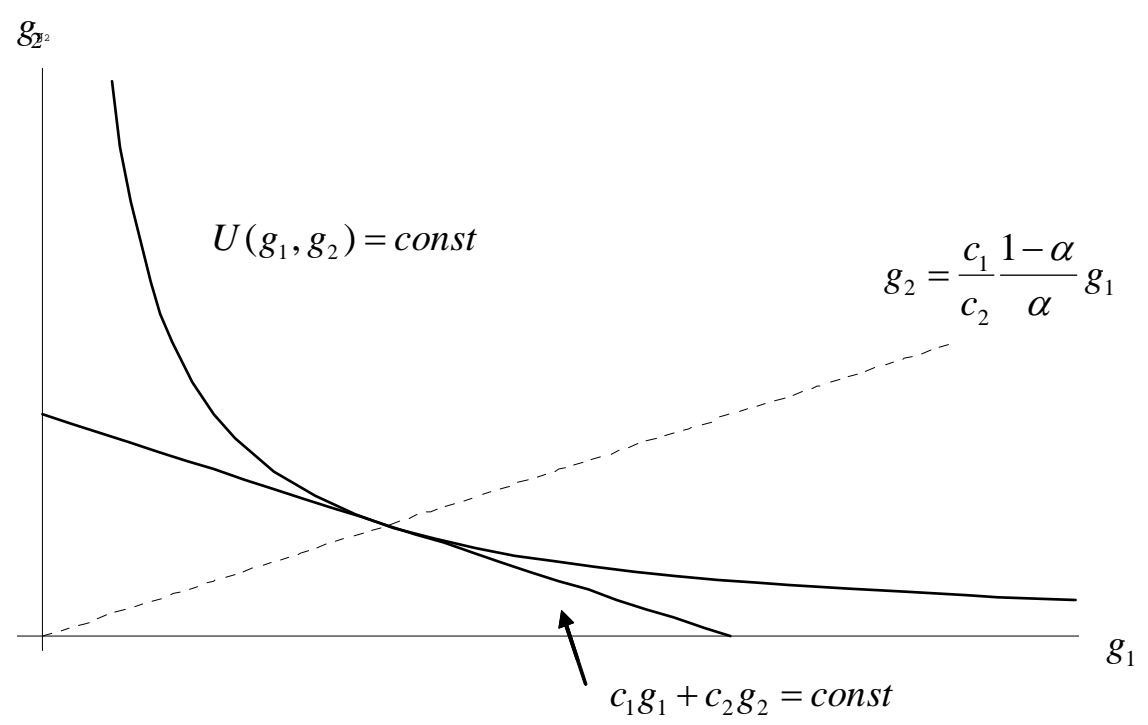

Figure 1: Fixed sharing rule vs. first-best.

On Figure 1 the solid curve and the solid line correspond to the federal social indifference curve and to the federal budget constraint, respectively. The budget constraint line has slope $\frac{c_{1}}{c_{2}}$. The dotted line has slope $\frac{c_{1}}{c_{2}} \frac{1-\alpha}{\alpha}$ and it represents the fixed sharing rule constraint expressed as $g_{2}=\frac{c_{1}}{c_{2}} \frac{1-\alpha}{\alpha} g_{1}$.

By manipulating the slope of the dotted curve, it is possible to restore the first-best allocation. The optimal share $\alpha^{*}$ that allows us to obtain the first-best is calculated as:

$$
\frac{1-\alpha^{*}}{\alpha^{*}}=\frac{c_{2} g_{2}^{F B}}{c_{1} g_{1}^{F B}}
$$

where $g_{i}^{F B}, i=1,2$ are given by (4). Therefore, the optimal share for region 1 is:

$$
\alpha^{*}=\frac{1}{1+\frac{c_{2}\left(\frac{\partial H_{2}}{\partial g_{2}}\right)^{-1}\left(c_{2}\right)}{c_{1}\left(\frac{\partial H_{1}}{\partial g_{1}}\right)^{-1}\left(c_{1}\right)}} .
$$

We can conclude that the larger the difference $\left(\alpha-\alpha^{*}\right)$, the further we are from the 
first-best allocation. In section 4 we analyze how the fixed regional shares are determined in a legislative bargaining setting.

The solution generated by the maximization of the unweighted sum of utilities is the most favorable setting to reach the first best with a fixed sharing rule. The other extreme is that one region acts as a dictator and selects the total budget for the public good. This region, denoted by $k$, will maximize its regional welfare under the fixed sharing rule, giving the following solution $g_{k}^{S R(k)}$ :

$$
\frac{d H_{k}\left(g_{k}^{S R(k)}\right)}{d g_{k}}=\frac{L_{k} c_{k}}{L \alpha_{k}} .
$$

Let us assume that the share $\alpha_{k}=\frac{L_{k}}{L}$, i.e. it is proportional to the population size. In the region $k$ the first-best allocation is then restored.

From formula (11) it is easy to calculate the total expenditure $G$ :

$$
G=\frac{c_{k}}{\alpha_{k}} g_{k}^{F B}
$$

as well as the equilibrium allocation for the other regions:

$$
g_{i}^{S R(k)}=\frac{\alpha_{i}}{c_{i}} \frac{c_{k}}{\alpha_{k}} g_{k}^{F B} \text { for } i \neq k .
$$

One can check that, in order to restore the first-best allocation in the other regions, the following condition should be satisfied:

$$
\frac{\alpha_{i}}{\alpha_{k}}=\frac{c_{i} g_{i}^{F B}}{c_{k} g_{k}^{F B}} \text { for } i \neq k,
$$

i.e. for two regions $i \neq k$ and $k$ the ratio of the regional shares should be the same as the ratio of the regional expenditures in the first-best allocation.

We have seen that the fixed regional share allocation have attractive properties when the regional shares are well chosen. The intuition for this result is simple: when a region is in power and can decide on the total expenditure on the public good $G$, even if the public good is paid by all the regions, the fixed share limits the regional benefit of extending the total expenditure on public goods. In other words, for every $\alpha$ euro spent in own region, there 
is automatically $(1-\alpha)$ euro to be spent in other regions - the fixed regional budget share imposes a kind of federal budget constraint to the region making the decision.

\section{Bargaining Stage}

The fixed regional share allocation works well if the shares are reasonable. What can we say about the determination of the regional budget shares? The fixed regional shares can be seen as the outcome of legislative bargaining at federal level that takes the form of a constitution. We demonstrate that the share of a region depends on its bargaining position. More precisely, the stronger the bargaining position of the region, the bigger its share in the federal budget.

To show this result, we employ a modified version of the legislative bargaining model from Baron and Ferejohn (1989). In this model $n \geq 3$ symmetric players decide how to divide the budget of size 1 according to a particular voting rule. We consider two cases. The first case is the simple majority rule: it is necessary to have $q$ out of $n$ votes to pass a proposal, where $q \in(n / 2, n)$. The second case is the unanimity rule: $q=n$ and $n \geq 2$. Unanimity may be a requirement if we want to fix the shares for a longer term such as in a constitution.

The players are risk-neutral and only concerned about their own share. Each player $i$ has probability $p_{i} \in(0,1)$ of being selected as a proposer to suggest a distribution among the

players, where $\sum_{i=1}^{n} p_{i}=1$. This player proposes a vector $\mathbf{x} \in \mathbb{R}_{+}^{n}$, with $\sum_{i=1}^{n} x_{i} \leq 1$, where $x_{i}$ is player $i$ 's share of the budget. As soon as the proposal is made, the others vote in favor or against. If a majority (at least $q-1$ ) of the players support it, the game ends and the budget is distributed according to the proposal, i.e. $x$ is implemented. Otherwise a new proposer is selected and the same procedure is repeated. The players discount the future payoffs by a factor $\delta \in[0,1]$.

Usually, in literature, the analysis is restricted to the stationary subgame perfect equilibria (SSPE). The existence result is provided by Banks and Duggan (2000) in a very general setting in which the space of outcomes can be any convex compact set and the utility func- 
tions are concave but otherwise unrestricted.

The main predictions of the model are the following: First, there is a property of immediate agreement. Even without discounting, there is a pressure to reach agreement in the first period because of the risk of being excluded afterwards. Second, only minimal winning coalitions form in equilibrium, since otherwise it would be a waste of resources for the agenda setter. Third, the proposer receives a disproportionately high share, because he/she always buys the cheapest minimal coalition and pays the minimum amount to its members simply to secure the acceptance of the proposal.

There is another interesting feature of the equilibrium which will be useful in our analysis. Baron and Ferejohn (1989) show, through the use of examples, that there are possibly multiple equilibria. However, Eraslan (2002) and Eraslan and McLennan (2006), using a quite general setup of the bargaining game, prove uniqueness of the expected payoffs generated by all the game's stationary equilibria.

In the two following sections 4.1 and 4.2 we look at two different approaches to explain regional shares by the political bargaining process.

\subsection{Regional Shares as Expected Payoffs}

In this section we consider the regional shares as fixed in the constitution, and suppose that they are calculated as ex ante expected payoffs obtained from the described bargaining game. Because of the appealing uniqueness property it is valid to do so.

\subsubsection{Sharing Rule under Unanimity Voting}

In this subsection we assume that it is necessary to have the votes of all $n \geq 2$ players to pass a proposal. Let $y_{i}$ denote player $i$ 's ex ante expected payoff. Then we can write the following system of equations:

$$
y_{i}=p_{i}\left(1-\sum_{\substack{j=1 \\ j \neq i}}^{n} \delta y_{j}\right)+\left(1-p_{i}\right) \delta y_{i} \text { for all } i=1 . . n .
$$


Thus, the expected payoff $y_{i}$ of player $i$ equals the first term of (13) if he/she is a proposer and the second term of (13) if he/she is not a proposer. With probability $p_{i}$, player $i$ is a proposer, and he/she buys the other players by proposing them their discounted expected payoffs, and he/she takes the remaining. Otherwise, with probability $1-p_{i}$ he/she receives his/her discounted expected payoff.

No-delay property implies

$$
\sum_{j=1}^{n} y_{j}=1,
$$

and therefore, after simplifications the equations (13) become

$$
y_{i}=p_{i} \text { for all } i=1 . . n \text {. }
$$

Thus, we have proved the following:

Proposition 1 In a unanimity voting system, the expected regional shares equal the probability of being a proposer for any discount factor $\delta \in(0,1)$.

We obtain that the expected share of player $i$ is equal to his/her probability of being selected as a proposer. If we think of $p_{i}$ as of player $i$ 's proposal power, then we can say that the expected share of the player is proportional to his/her proposal power. Notice that this result is independent of the discount factor $\delta$.

If the probability of being a proposer is proportional to the population size of the region, such as in a proportional representation system, the resulting shares $\alpha_{i}$ are also proportional to the population size.

\subsubsection{Sharing Rule under the Majority Voting}

In this section we consider the following situation: each player has one vote and $q$ votes are necessary to approve the decision. We take $n=2 l+1, l \geq 1$ and $q \geq l+1$. For the rest of the section we assume that the players have the same discount factor $\delta$, which is close to 1. As before, $y_{i}$ denotes player $i$ 's ex ante expected payoff. Without loss of generality we suppose that the players are enumerated in such a way that $y_{1} \leq \ldots \leq y_{n}$. 
Proposition 2 (Zaporozhets (2006))In a majority voting system either

(i) $p_{i}<\frac{1}{n+1-q}$ for all $i=1 \ldots n$, then vector of SSPE payoffs is $\left(\frac{1}{n}, \ldots, \frac{1}{n}\right)$. Such SSPE is characterized by the fact that each player is indifferent to propose an allocation to any minimal winning coalition, which includes himself. Or

(ii) there exists $k \geq q$ such that

$$
p_{i}<\frac{1}{k+1-q} \sum_{l=1}^{k} p_{l}<p_{j} \text { for any } i=1 \ldots k \text { and any } j=k+1 \ldots n,
$$

and the vector of SSPE payoffs is given by

$$
\begin{gathered}
y_{i}=y=\frac{\sum_{l=1}^{k} p_{l}}{(k+1-q)+(q-1) \sum_{l=1}^{k} p_{l}} \text { for any } i=1, \ldots, k \text { and } \\
y_{j}=\frac{(k+1-q) p_{j}}{(k+1-q)+(q-1) \sum_{l=1}^{k} p_{l}} \text { for any } j=k+1, \ldots, n .
\end{gathered}
$$

Remark 1 1. Result (i) can be interpreted in the following way: if the distribution of the proposal power is relatively close to the uniform distribution then we obtain the uniform sharing rule.

2. If conditions (14) in part (ii) are satisfied then it can be shown that

$$
\begin{aligned}
p_{i} & <\frac{1}{n+1-q} \text { for } i=1 \ldots k \text { as before, but } \\
p_{j} & >\frac{1}{n+1-q} \text { for at least one } j \in\{k+1, \ldots n\} .
\end{aligned}
$$

So, the intuition of the result (ii) is the following: when the distribution of the proposal power is too different from the uniform distribution, the sharing rule is not uniform anymore.

3. The following properties are satisfied in this case: It is easy to see that $\partial y_{i} / \partial p_{i}>0$ for any $i=1 \ldots n$. Next, ex ante expected payoffs of players $1 . . k$ are smaller than $1 / n$; and then expected payoffs of at least some of the other players should be larger than $1 / n$.

For case $n=3$ Proposition 2 provides the following results. Suppose, there is a "strong" player with the probability of being selected as a proposer larger than $1 / 2$. Without loss of generality we can assume that it is player 3. Then his/her expected payoff is:

$$
y_{3}=\frac{p_{3}}{1+p_{1}+p_{2}}
$$


and each of the two other players gets

$$
y_{i}=\frac{p_{1}+p_{2}}{1+p_{1}+p_{2}}, i=1,2
$$

In this case it is easy to show that $y_{3}$ is larger than $1 / 3$, and $y_{1}$ and $y_{2}$ are smaller than $1 / 3$.

If there is no such a player, i.e. for all $i=1,2,3$ probabilities $p_{i}<1 / 2$, everybody receives exactly $1 / 3$.

\subsection{Implementation of Regional Shares through Trigger Strategies}

Up to now we have showed that the fixed regional sharing rule can be explained in terms of the expected payoffs from the legislative bargaining game. Now, we modify our setting slightly. As before, an agenda setter is chosen following a specified probability distribution and the legislators discount future payoffs according to the discount factor $\delta \in(0,1)$. We suppose the regions agree in advance that, each period, whoever is becoming an agenda setter will propose proportional distribution of the fixed federal budget, i. e. he/she proposes shares $\left(\alpha_{i}\right)_{i=1 . . n}$.

In this subsection we assume that, if at some stage, the chosen agenda setter decides to deviate from the given distribution, the other regions will play a non-cooperative one-stage equilibrium during the following periods. The agenda setter will therefore choose a coalition composed of $q-1$ other regions, and the regions outside this winning coalition get no public good at all, even though they will bear the cost of taxes. Next, the agenda-setter will spend only as much as necessary to keep the members of the winning coalition barely as well off as with the default policy (zero utility level). Lastly, the agenda setter will choose regions that are "cheapest" to buy off, i.e. that value a unit of the public good more than the others.

We are going to investigate a simple case, in which the legislators have the same quasilinear utility $u\left(g_{i}\right)$ from the consumption of the local public good $g_{i}$ :

$$
u\left(g_{i}\right)=(1-t) L_{i}+H\left(g_{i}\right)
$$


where $L_{i}$ is the labor supply in each region $i$. Tax $t$ is determined by the federal budget constraint:

$$
t L=\sum_{i=1}^{n} c_{i} g_{i},
$$

where $L=\sum_{i=1}^{n} L_{i}$ and $c_{i}$ is the unit cost of public good provision, and, for simplicity, it is taken to be 1 . Therefore, the tax level is just

$$
t=\frac{g}{L}
$$

The benefit function $H\left(g_{i}\right)$ is identical for all regions, and as before, we assume that

$$
H(0)=0, H^{\prime}\left(g_{i}\right)>0 \text { and } H^{\prime \prime}\left(g_{i}\right)<0, i=1 . . n \text {. }
$$

In a one-period bargaining game a specified agenda setter chooses coalition $M$ of size $q-1$ and offers each of the coalition member as much as is necessary to restore his/her default utility, i.e.

$$
u\left(g_{i}\right)=L_{i} \text { for each } i \in M \text {. }
$$

Thus, the level of public good each member of the coalition $M$ gets is defined as:

$$
H\left(g_{i}\right)=\frac{L_{i}}{L} g \text { for any } i \in M,
$$

where $g$ is the size of the federal funds to be distributed. It is easy to see that coalition $M$ will contain regions with the smallest $L_{i}$.

We denote by $g_{m}$, the total amount of public good distributed to the members of $M$, i. e.

$$
g_{m}=\sum_{i \in M} H^{-1}\left(\frac{L_{i}}{L} g\right) .
$$

The non-members do not get any public good at all, however they bear the costs:

$$
u\left(g_{i}\right)=(1-t) L_{i}=L_{i}-g \frac{L_{i}}{L} \text { for any } i \notin M .
$$


We would like to identify the conditions under which the deviation is not sustainable. If at some stage of the game, legislator $i$ is chosen to be a proposer and he/she decides to deviate, his/her expected payoff would be:

$$
\begin{aligned}
& {\left[L_{i}-g \frac{L_{i}}{L}+H\left(g-g_{m}\right)\right]+} \\
& \sum_{t=1}^{\infty} \delta^{t}\left[p_{i}\left(L_{i}-g \frac{L_{i}}{L}+H\left(g-g_{m}\right)\right)+\left(1-p_{i}\right)\left(L_{i}-g \frac{L_{i}}{L}\right)\right] .
\end{aligned}
$$

The first term is the maximum the legislator could get by deviating, and the second term reflects the infinite punishment stage: the legislator can receive the maximum only if he/she is chosen as a proposer and, if not, he/she simply bears the cost.

Expected payoff (17) should be compared with his/her expected payoff under the assumption that he/she cooperates through all the periods, i.e. he/she gets share $\alpha_{i}$ :

$$
\sum_{t=0}^{\infty} \delta^{t}\left[L_{i}-g \frac{L_{i}}{L}+H\left(\alpha_{i} g\right)\right] .
$$

That is, we examine under which conditions the following inequality holds true:

$$
\frac{1}{1-\delta} H\left(\alpha_{i} g\right) \geq H\left(g-g_{m}\right)+\frac{\delta}{1-\delta} p_{i} H\left(g-g_{m}\right) .
$$

Multiplying by $(1-\delta)$ and rearranging the terms we get:

$$
\delta \geq \frac{H\left(g-g_{m}\right)-H\left(\alpha_{i} g\right)}{\left(1-p_{i}\right) H\left(g-g_{m}\right)} .
$$

The deviation is not sustainable if and only if the right hand side of (19) is smaller than 1.

One can check that it is smaller than 1 if

$$
H\left(g-g_{m}\right)<\frac{1}{p_{i}} H\left(\alpha_{i} g\right) .
$$

Since the benefit function $H$ is concave

$$
\frac{1}{p_{i}} H\left(\alpha_{i} g\right) \geq \frac{\alpha_{i}}{p_{i}} H(g)
$$


Assuming that $\alpha_{i}=p_{i}$ we get that

$$
\frac{1}{p_{i}} H\left(\alpha_{i} g\right) \geq H(g)>H\left(g-g_{m}\right)
$$

and therefore (20) is satisfied. Thus, we showed that under additional assumption $\alpha_{i}=p_{i}$ there exists threshold $\bar{\delta}<1$ such that for $\delta \geq \bar{\delta}$ the fixed sharing rule can be implemented.

\section{Numerical Illustration for Railway Investments in Belgium}

Belgium is a federal country that consists of three regions: Brussels (capital and centrally located), Flanders and Walloon region. Historically a tradition developed that only railway investment plans satisfying the rule "60\% (for Flanders) and $40 \%$ (for Wallonia)" can be accepted by the federal parliament. We calibrate a small numerical example to illustrate the effect of the fixed sharing rule.

\subsection{Calibration of the Model}

Let us denote by $f$ and $w$ the Flanders and Walloon regions respectively. We assume that the observed equilibrium is a fixed share equilibrium with fixed shares $60 \%$ for Flanders and $40 \%$ for Wallonia.

We use the following specification:

$$
H_{i}\left(g_{i}\right)=2 \lambda_{i} \sqrt{g_{i}}, i=f, w,
$$

where $\lambda_{i}$ is a calibration parameter for the benefit function, and assume average cost per unit of rail investment $c_{i}$ in each region $i=f, w$. The rail geography of Belgium is such that many passengers go to Brussels but almost do not use the infrastructure in the other region. Brussels is the capital region in the middle of the country with Walloon region situated to the south and the Flanders region situated to the north. We can therefore neglect regional 
spillovers between Flanders and Wallonia. The rail investments in Brussels are considered to benefit the whole federation and are kept outside the allocation mechanism.

For the calibration of the model we need two assumptions. First, it is often claimed that the construction cost is higher in the more hilly Wallonia than in Flanders. We normalize the Walloon construction cost $c_{w}$ to one and assume that $c_{f}=0.85$. Second, we assume that the density of the railway network ${ }^{2}$ is 1.54 times higher in Flanders than in Wallonia. We use this observation to assume that the benefit scale parameter $\lambda_{i}$ is larger for Flanders:

$$
\lambda_{f}=1.54 \lambda_{w}
$$

From "Nationaal Instituut voor de Statistiek" (NIS) 2001 we know that

$$
L_{f}=5,952,552 \text { and } L_{w}=3,346,457 .
$$

In 2001, Belgium invested 532.6 million euro in railway infrastructure, so we have:

$$
G=c_{w} g_{w}^{S R}+c_{f} g_{f}^{S R}=532.6 \text { million euro. }
$$

We know that the share of Flanders is $\alpha=0.6$. From (21) and the fact that $c_{f} g_{f}=\alpha G$ and $c_{w f} g_{w}=(1-\alpha) G$ we can easily calculate the total investment levels for the fixed sharing rule in each region:

$$
\begin{aligned}
& g_{f}^{S R}=5.326 \times 10^{8} * 0.6 / 0.85=376 \text { million euro and } \\
& g_{w}^{S R}=5.326 \times 10^{8} * 0.4=213 \text { million euro }
\end{aligned}
$$

We assumed that the observed equilibrium satisfies (9):

$$
\frac{\alpha}{c_{f}} \frac{\lambda_{f}}{\sqrt{g_{f}}}+\frac{1-\alpha}{c_{w}} \frac{\lambda_{w}}{\sqrt{g_{w}}}=1
$$

From this condition it is easy to find $\lambda_{w}$ :

$$
\left(\frac{1.54 \alpha}{0.85 \sqrt{g_{f}}}+\frac{1-\alpha}{\sqrt{g_{w}}}\right) \lambda_{w}=1
$$

and therefore,

$$
\lambda_{w}=\left(\frac{1.54 * 0.6}{0.8 * \sqrt{3.76} \times 10^{4}}+\frac{0.4}{\sqrt{2.13} \times 10^{4}}\right)^{-1}=11981 .
$$

\footnotetext{
${ }^{2}$ The density is the number of people per kilometer of rail. In Flanders the density is 5952552/1848.7 = 3219.9 and in Wallonia it is $3346457 / 1605.3=2084.6$.
} 


\subsection{Scenarios}

Taking all parameters into consideration, we are able to compute alternative equilibria. The first-best allocation becomes:

$$
g_{f}^{F B}=\left(\frac{11981 * 1.54}{0.85}\right)^{2}=471 \text { million euro, }
$$

and

$$
g_{w}^{F B}=\left(\frac{\lambda_{w}}{c_{w}}\right)^{2}=(11981)^{2}=144 \text { million euro. }
$$

Thus, in the first-best allocation Wallonia gets $23 \%$ and $77 \%$ goes to Flanders.

From (10) the optimal share $\alpha^{*}$ that could generate the first best in this case would be:

$$
\alpha^{*}=\frac{1}{1+\frac{g_{w}^{F B}}{g_{f}^{F} B}}=\frac{1}{1+\frac{144}{471}}=0.767 .
$$

So, the difference $\left(\alpha^{*}-\alpha\right)$ is 0.167 .

One can notice that $L_{f} / L=0.64$ which is close to $\alpha=0.6$.

The numerical results for alternative equilibria are presented in Table 1, where utility levels are given in millions of euro. The federal utility (the first column) is defined as the simple sum of the regional utilities.

Table 1: Numerical Example.

\begin{tabular}{l|llllll} 
Allocations & $\begin{array}{l}\text { Utility } \\
(\mathbf{f e d})\end{array}$ & $\begin{array}{l}\text { Utility } \\
(\mathbf{F})\end{array}$ & $\begin{array}{l}\text { Utility } \\
(\mathbf{W})\end{array}$ & $\begin{array}{l}\text { Invest- } \\
\text { ment }(\mathbf{F})\end{array}$ & $\begin{array}{l}\text { Invest- } \\
\text { ment (W) }\end{array}$ & Efficiency \\
\hline \hline $\mathrm{FB}$ & 553 & 459 & 95 & $100 \%$ & $100 \%$ & $100 \%$ \\
$\mathrm{CP}$ & 157 & 46 & 111 & $200 \%$ & $630 \%$ & $28 \%$ \\
$\mathrm{SR}$ & 542 & 381 & 161 & $80 \%$ & $148 \%$ & $98 \%$ \\
$\mathrm{SR}(\mathrm{f})$ & 540 & 381 & 159 & $88 \%$ & $163 \%$ & $98 \%$ \\
$\mathrm{SR}(\mathrm{w})$ & 538 & 375 & 163 & $66 \%$ & $123 \%$ & $97 \%$
\end{tabular}

We see that the common pool (CP) equilibrium indeed performs very poorly, with an efficiency of $29 \%$ of the first-best (FB) equilibrium. The fixed regional sharing rule (SR) 
with different specifications produces relatively good results. SR represents the equilibrium obtained when the federal government chooses the total level of public goods that maximizes the sum of regional utilities but respects the regional shares (see (9)). This could be seen as the outcome of a coalition government. Equilibria $\mathrm{SR}(\mathrm{f})$ and $\mathrm{SR}(\mathrm{w})$ correspond to the case where the same regional shares are used but where the total supply of public goods maximizes the welfare function of the regions $\mathrm{f}$ or $\mathrm{w}$. The result is that the three fixed share equilibria (SR, $\mathrm{SR}(\mathrm{f})$ and $\mathrm{SR}(\mathrm{w})$ ) all perform striking much better in efficiency terms than the common pool equilibrium. The main explanation for this result is that, in the fixed sharing equilibrium, the proposer is limited in exploiting his/her agenda setting power: whatever extra supply of public goods he/she wants his/her region implies that he/she will have to also supply public goods to the other regions.

To check that our results are not directly follow from a particular choice of parameters we provide a sensitivity test. We change the power in the utility function from 0.5 to 0.25 and 0.75 , respectively. The performed calculations are presented in the following Table 2 .

Table 2: Sensitivity Test.

\begin{tabular}{l|lll|lll} 
& \multicolumn{3}{|c|}{ power 0.25 } & \multicolumn{3}{c}{ power $\mathbf{0 . 7 5}$} \\
\hline Allocations & $\begin{array}{l}\text { Invest } \\
\text { Invest }\end{array}$ & Efficiency & Invest & Invest & Efficiency \\
& $(\mathbf{F})$ & $(\mathbf{W})$ & & $(\mathbf{F})$ & $\mathbf{( W )}$ & \\
\hline \hline $\mathrm{FB}$ & $100 \%$ & $100 \%$ & $100 \%$ & $100 \%$ & $100 \%$ & $100 \%$ \\
$\mathrm{CP}$ & $158 \%$ & $341 \%$ & $87 \%$ & $398 \%$ & $3981 \%$ & $24 \%$ \\
$\mathrm{SR}$ & $92 \%$ & $115 \%$ & $99.9 \%$ & $53 \%$ & $325 \%$ & $98 \%$ \\
$\mathrm{SR}(\mathrm{f})$ & $92 \%$ & $115 \%$ & $99.9 \%$ & $77 \%$ & $471 \%$ & $98 \%$ \\
$\mathrm{SR}(\mathrm{w})$ & $92 \%$ & $115 \%$ & $99.9 \%$ & $25 \%$ & $153 \%$ & $97 \%$
\end{tabular}

As one can see for the steeper utility function, performance of the different sharing rules improves. We also tested that equal regional costs $c_{f}=c_{w}$ do not change the main conclusions. 


\section{Conclusion}

We used a stylized model to investigate different allocation of regional investments across regions of a federal state and the welfare implications. The fixed regional shares allocation appears to be relatively efficient if the regional shares are reasonable. The regional shares can be shown to be a function of the relative proposal power of the regions.

\section{References}

[1] Banks J. S. and J. Duggan, 2000. "A Bargaining Model of Collective Choice", American Political Science Review 94(1), 73-88.

[2] Baron, D. P. and J. A. Ferejohn, 1989. "Bargaining in Legislatures", American Political Science Review 83, 1181-1206.

[3] Baron, D.P., 1991. "A Spatial Bargaining Theory of Government Formation in Parliamentary Systems", American Political Science Review 85(1), 137-164.

[4] Besley, T. and S. Coate, 2003. "Centralized versus Decentralized Provision of Local Public Goods: A Political Economy Approach", Journal of Public Economics 87, 26112637.

[5] Dixit, A., Grossman, G.M. and R. Helpman, 1997. "Common Agency and Coordination: General Theory and Application to Government Policy Making", Journal of Political Economy, 105(4), 725-769.

[6] Eraslan, H., 2002. "Uniqueness of Stationary Equilibrium Payoffs in the Baron-Ferejohn Model", Journal of Economic Theory 103, 11-30.

[7] Eraslan, H., A. McLennan, 2006. "Uniqueness of Stationary Equilibrium Payoffs in Coalitional Bargaining", Working Paper. 
[8] Knight, B., 2002. "Endogenous Federal Grants and Crowd-out of State Government Spending: Theory and Evidence from the Federal Highway Aid Program", American Economic Review 92(1), 71-92.

[9] Knight, B., 2004. "Parochial Interests and the Centralazed Provision of Local Public Goods: Evidence from Congressional Voting on Transportation Projects", Journal of Public Economics 88, 845-866.

[10] Knight, B., 2005. "Estimating the Value of Proposal Power", American Economic Review 95(5), 1639-1652.

[11] Montero, M., 2006. "Noncooperative Foundations of the Nucleolus in Majority Games", Games and Economic Behavior, 54(2) 380-397.

[12] Montero, M., 2007. "Inequity Aversion May Increase Inequity", The Economic Journal, 117 192-204.

[13] Moulin, H., 2002. "Axiomatic Cost and Surplus Sharing" in A.K. Sen and K. Suzumura,eds., Handbook of Social Choice and Welfare, vol. 1, ch. 6, pp. 289-357.

[14] Persson, T., 1998. "Economic Policy and Special Interest Politics", The Economic Journal, 108(447), 310-327.

[15] Snyder, J.M., Ting, M. M. and S. Ansolabehere, 2005. "Legislative Bargaining under Weighted Voting", American Economic Review 95(4), 981-1004.

[16] Tullock, G., 1959. "Some problems of majority voting", Journal of Political Economy $67,571-579$.

[17] Weingast, B.R., Shepsle K.A. and C. Johnsen, 1981. "The Political Economy of Benefits and Costs: A Neoclassical Approach to Distributive Politics", Journal of Political Economy 89(4), 642-664.

[18] Young H.P., Okada, N. and T. Hashimoto, 1982. "Cost Allocation in Water Resources Development", Water Resources Research 18(3), 463-475. 
[19] Zaporozhets, V. "Essays on Political Economy and Social Choice", Ph.D. Thesis, University of Toulouse, December 2006. 